\title{
Neurophysiological alterations in the nucleus reuniens of a mouse model of Alzheimer's disease
}

\author{
D.A. Walsh ${ }^{1}$, J.T. Brown ${ }^{1}$ and A.D. Randall ${ }^{1 *}$ \\ ${ }^{1}$ Institute of Biomedical and Clinical Sciences, University of Exeter Medical School, Hatherly \\ Laboratory, Exeter, EX4 4PS.
}

*Corresponding author

Email: A.Randall@exeter.ac.uk 
bioRxiv preprint doi: https://doi org/10.1101/643023; this version posted May 20 2019. The copyright holder for this preprint (which was not certified by peer review) is the author/funder, who has granted bioRxiv a license to display the preprint in perpetuity. It is made available under aCC-BY-NC-ND 4.0 International license.

\section{Key Points}

- Alterations in the neurophysiology of hippocampal and cortical neurons has been linked to network hyperexcitability in mouse models of amyloidopathy.

- The nucleus reuniens $(\mathrm{Re})$ is part of a cognitive network involving the hippocampal formation and prefrontal cortex. Increased cellular activity in Re has been linked to the generation of hippocampal-thalamo-cortical seizure activity in $\mathrm{J} 20$ mice.

- Re neurons display hyperpolarised resting membrane potentials in $\mathbf{J 2 0}$ mice. Passive membrane properties are unaffected by transgene expression. Re neurons recorded from J20 mice did not exhibit increased excitability in response to depolarising current stimuli but did exhibit an increased propensity to rebound burst following hyperpolarising current stimuli. This increased rebound firing was not a result of changes in T-type $\mathrm{Ca}^{2+}$ conductances. Finally we observed a decrease in AP width.

- These results help us understand how altered Re cellular neurophysiology may contribute to hippocampal-thalamo-cortical hyperexcitability in J20 mice.

\section{1}

2

3

4

5

6

7

8

\section{Abstract}

Transgenic mice that overproduce beta-amyloid $(A B)$ peptides exhibit neurophysiological alterations at the cellular, synaptic and network levels. Recently, increased neuronal activity in nucleus reuniens $(\mathrm{Re})$, has been linked to hyperexcitability within hippocampal-thalamo-cortical networks in the J20 mouse model of amyloidopathy. Here in vitro whole-cell patch clamp recordings were used to compare old pathology-bearing J20 mice and wild-type controls to examine whether alterations to the intrinsic electrophysiological properties of Re neurons could contribute to the amyloidopathyassociated Re hyperactivity. A greater proportion of Re neurons displayed a hyperpolarised membrane potential in J20 mice without changes to the incidence or frequency of spontaneous action potential (AP) generation. Passive membrane properties were independent of transgene expression. Re neurons recorded from $\mathrm{J} 20$ mice did not exhibit increased AP generation in response to depolarising current stimuli but did exhibit an increased propensity to rebound burst following hyperpolarising current stimuli. This increase in rebound firing does not appear to result from alterations to T-type calcium channels. Finally, in J20 mice there was an $~ 8 \%$ reduction in spike width, similar to what we and others have reported in CA1 pyramidal neurons from multiple amyloidopathy mice. We conclude that alterations to the intrinsic properties of Re neurons may contribute to the hyperexcitability observed in hippocampal-thalmo-cortical circuits under pathological $A \beta$ load.

\section{Introduction}

The excess generation and/or reduced clearance of beta-amyloid (A $\beta$ ) peptides in the central nervous system (CNS) of patients with Alzheimer's disease (AD) leads of the accumulation of amyloid plaques, a core pathological feature of the disease. The amyloid hypothesis of AD states that this imbalance between production and removal of $A \beta$ within the CNS is a key determinant of the functional deficits, and accompanying neuronal loss, associated with AD (Hardy \& Higgins, 1992; Selkoe \& Hardy, 2016). 
bioRxiv preprint doi: https://doi.org/10.1101/643023; this version posted May 20, 2019. The copyright holder for this preprint (which was not certified by peer review) is the author/funder, who has granted bioRxiv a license to display the preprint in perpetuity. It is made available under aCC-BY-NC-ND 4.0 International license.

The advent of mouse models of amyloidopathy has provided researchers with an incredibly powerful tool for studying the functional and behavioural abnormalities associated with an increased $A \beta$ load in the CNS (McGowan et al., 2006; Randall et al., 2010). These transgenic models typically express causal genetic mutations associated with familial AD, resulting in overproduction of pathological forms of $A \beta$. One such model which is widely used to model amyloid pathology is J20 (PDGF-APPSw, Ind) mice (Mucke et al., 2000). This transgenic line overexpresses human amyloid precursor protein (APP) with two mutations (Swedish and Indiana) under the platelet-derived growth factor (PDGF) promotor, resulting in increased $A \beta$ production throughout the CNS. J20 mice recapitulate many of the hallmarks of AD pathology including amyloid plaque deposition (Wright et al., 2013), synaptic loss (Hong et al., 2016), cognitive impairment (Cheng et al., 2007; Wright et al., 2013), and network hyper-excitability (Palop \& Mucke, 2009; Verret et al., 2012; Hazra et al., 2016).

The majority of studies investigating neurophysiological deficits in models of amyloidopathy have focused on altered synaptic function (Jacobsen et al., 2006; Saganich et al., 2006; Witton et al., 2010) and associated functional abnormalities within defined neural networks, most commonly in the hippocampus and cortex. More recently, evidence has accumulated that alterations in the intrinsic properties of discrete neural populations appear to be a common phenotype arising from overexpression of $A \beta$, with changes consistently reported in intrinsic excitability profile and AP waveform (Brown et al., 2011; Wykes et al., 2012; Kerrigan et al., 2014; Tamagnini et al., 2015). With the assumption that neurophysiological changes at the level of single neurons will manifest themselves at the level of complex network activity underlying cognitive processing, these reports have provided important insight into the emergence of functional deficits characteristic of $A D$. However, as with work on synaptic function, such studies have focused almost exclusively on alterations to the intrinsic properties of neurons in the hippocampus or cerebral cortex.

In the last 25 years there has been a growing appreciation that specific thalamic nuclei, making up a portion of the limbic thalamus, are important at various levels of cognitive function (Aggleton \& Brown, 1999; Aggleton, 2014). One of these the nucleus reuniens (Re), a midline thalamic nucleus, forms strong reciprocal connections with both the hippocampus and medial prefrontal cortex (Vertes et al., 2015). Interest in Re has grown dramatically in recent years (Cassel et al., 2013), with considerable evidence indicating a role for the Re in various forms of memory (Hembrook \& Mair, 2011; Cholvin et al., 2013; Hallock et al., 2013; Pereira de Vasconcelos \& Cassel, 2015) and the emergence of oscillatory synchrony between the HPC and mPFC during cognitive tasks (Hallock et al., 2016; Roy et al., 2017; Kafetzopoulos et al., 2018). Spatial and goal-oriented neurons have been described in Re (Jankowski et al., 2014, 2015; Ito et al., 2015) and experimental inactivation of this area results in spatial deficits, reflecting those commonly observed in both AD patients and mouse 
models of AD. Recently a study, has linked increased c-fos immunoreactivity (>300\%) in Re to cortical epileptiform activity frequently described in J20 mice (Hazra et al., 2016).

In this initial observational study, we present data on the intrinsic membrane properties of Re neurons recorded from 12-14 month old J20 neurons and age-matched wild-type controls. To our knowledge, this is the first study which describes alteration in the intrinsic properties of Re neurons in a rodent model of dementia. The implications of these alterations in the context of aberrant network activity will be discussed.

\section{Methods}

\section{Ethical approval}

All work in this study was approved by the University of Exeter Animal Welfare Ethical Review Board. Animals were sacrificed in accordance with schedule 1 of the UK Animals (Scientific Procedures) Act 1986 and the subsequent amendments to the regulations of 2012, as implemented in response to directive 2010/63/EU of the European Parliament and of the Council on the protection of animals used for scientific purposes.

\section{Animals and tissue preparation}

Male transgenic (TG) J20 mice (background strain: C57-BI/6J) and wild-type (WT) littermate controls were bred in house at the University of Exeter. They were subsequently housed on a 12:12 light/dark cycle and granted $a b$ libitum access to food and water. This study used mice of approximately 13 months of age (WT, mean 13.1 months, range 12.1-14.2 months, $n=12 ; \mathrm{TG}$, mean 13 months, range 12.4-14.3 months, $n=13$ ). Following cervical dislocation, the brain was rapidly resected and placed within an ice-cold sucrose-based slicing medium consisting of (in mM): 189 Sucrose, 10 D-Glucose, 26 $\mathrm{NaHCO}_{3}, 3 \mathrm{KCl}, 5 \mathrm{Mg}_{2} \mathrm{SO}_{4}, 0.1 \mathrm{CaCl}_{2}, 1.25 \mathrm{NaH}_{2} \mathrm{PO}_{4}$. Coronal sections of $300 \mu \mathrm{m}$ thickness were sliced using a Leica VT1200 vibratome, and allowed to recover at room temperature for at least one hour prior to recording. Slice recovery was in our standard recording aCSF, composed of (in mM): $124 \mathrm{NaCl}$, $3 \mathrm{KCl}, 24 \mathrm{NaHCO}_{3}, 1.25 \mathrm{NaH}_{2} \mathrm{PO}_{4}, 2 \mathrm{CaCl}_{2}, 1 \mathrm{MgSO}_{4}, 10 \mathrm{D}$-Glucose, gassed with carbogen (i.e. 95\% $\mathrm{O}_{2}$ $\left./ 5 \% \mathrm{CO}_{2}\right)$. A single coronal section containing the rostral Re was identified as described previously (Walsh et al., 2017).

\section{Electrophysiological recordings}

For recordings the slice containing rostral Re was transferred to a commercial submerged recording chamber (Warner Instruments), which was mounted on the stage of an upright microscope (Olympus $\mathrm{BX51)}$. The chamber was perfused with a continuous flow of temperature-controlled $\left(32-33^{\circ} \mathrm{C}\right)$, carbogen bubbled, aCSF. Re neurons were visualised using infrared differential interference contrast 
optics and a CMOS USB 2.0 camera (ThorLabs). All recordings were made using the patch clamp technique. Pipettes (3-5 M 2 ) were fabricated from borosilicate glass capillaries using a P-97 Flaming Brown micropipette puller. Pipettes were filled with either a potassium-gluconate based internal solution (for current-clamp recording) composed of (in mM): $140 \mathrm{~K}$-gluconate, $10 \mathrm{NaCl}, 10 \mathrm{HEPES}$ free acid, 0.2 EGTA, 0.3 Na-GTP, $4 \mathrm{Mg}$-ATP, pH adjusted to 7.3 with $\mathrm{KOH}$, or a cesium methanesulfonate based internal solution (voltage-clamp recording) composed of (in $\mathrm{mM}$ ): $130 \mathrm{CsMeSO}_{4}, 20 \mathrm{NaCl}, 10$ HEPES free acid, 0.2 EGTA, 0.3 Na-GTP, 4 Mg-ATP, pH adjusted to 7.3 with $\mathrm{CsOH}$. All recordings were made with a Multiclamp 700B amplifier (Molecular Devices) and digitised with a Digidata 1440A interface (Molecular Devices). All data were stored on a personal computer (Hewlett-Packard) using pClamp 10.4 software.

\section{Data analysis}

Data were generally analysed using custom-written MATLAB scripts or, on occasion, using pClamp 10.4 software. A junction potential error of either $-15 \mathrm{mV}$ (K-Gluconate internal) or $-9 \mathrm{mV}\left(\mathrm{CsMeSO}_{4}\right.$ based internal) was corrected for arithmetically during data analysis. Statistical significance between genotypes was assessed using unpaired two-tailed Student's t-tests, Mann-Whitney $U$ tests, Kolmogorov-Smirnov tests or repeated-measure two-way analysis of variance (ANOVA) as appropriate, within the SPSS Statistics 22 software platform (IBM). Figures were prepared using Origin 2015.

\section{Results}

Previous recordings made within our lab from young adult (16-18 weeks) male mice indicate that Re neurons typically display a relatively depolarised resting membrane potential $\left(\mathrm{V}_{\mathrm{m}}\right)$ and an associated propensity to fire spontaneous action potentials (APs) in the absence of any external depolarising input (Walsh et al., 2017). To assess whether the spontaneous firing behaviours of Re neurons differed between WT and TG mice, $V_{m}$ was recorded, in the absence of exogenous stimuli, for $60 \mathrm{~s}$ following breaking in to the whole cell mode. Commensurate with previous findings, the majority of Re neurons recorded from both WT and TG mice exhibit a depolarised (>-70 mV) membrane potential (WT, median $-63.5 \mathrm{mV}, \mathrm{TG}$, median $-66.9 \mathrm{mV}$ ). However the proportion of rostral Re neurons exhibiting a relatively hyperpolarised $V_{m}$ was increased in $J 20$ mice when compared to WT controls (Fig $1 A, W T, n$ $=43 ; \mathrm{TG}, \mathrm{n}=49 ; \mathrm{p}=0.05$, Kolmogorov-Smirnov test). As illustrated in figure $1 \mathrm{~A}$, approximately $40 \%$ of Re neurons recorded from TG mice displayed a $V_{m}$ of $\leq-75 \mathrm{mV}$, compared to $\sim 10 \%$ of WT controls. Interestingly, this did not correspond to a significant decrease in the number of neurons exhibiting spontaneous AP generation in the absence of applied stimuli (Fig 1B, p = 0.25, Chi-squared test), with the majority of neurons of both genotypes firing at least 1 AP during the $60 \mathrm{~s}$ recording period. 
We have previously described 4 different populations of Re neurons based on spontaneous firing behaviours (Walsh et al., 2017) and found, predictably, that $V_{m}$ varies between these populations. As such, the increased proportion of hyperpolarised neurons in $J 20$ mice could be a manifestation of an increase in the relative proportion of active neurons displaying low firing frequencies associated with hyperpolarised $V_{m}$. To test this we examined the population distributions of spontaneous neuronal firing frequencies. Firing frequency was calculated by dividing the number of APs observed within the $60 \mathrm{~s}$ recording by 60 . No difference was observed between WT and TG mice (Fig 1C, WT, $n=32 ;$ TG, $n$ $=31, p=0.64$, Kolmogorov-Smirnov test). Another possible explanation for the change in $V_{m}$ without a parallel change in either the proportion of cells exhibiting APs or the frequency of spontaneous APs is a change in the $V_{m}$ of neurons which generate no spontaneous APs. However, the $V_{m}$ of quiescent neurons was not significantly different between WT and TG neurons (WT, mean -74.4 $\pm 2.8 \mathrm{mV}, \mathrm{n}=$ $11 ; \mathrm{TG}$, mean $-76.3 \pm 2.2 \mathrm{mV}, \mathrm{n}=18 ; \mathrm{p}=0.59$, unpaired, two tailed student's t-test, data not shown).

A
B

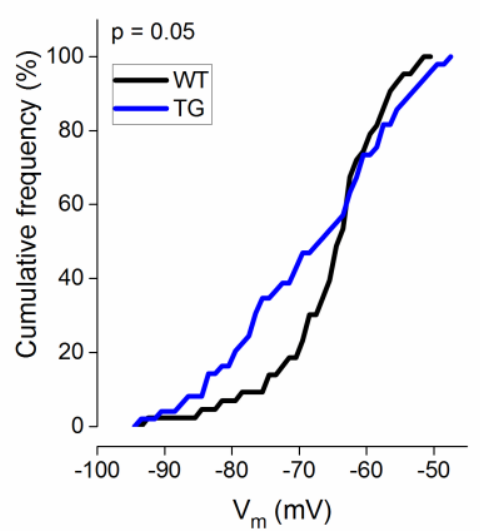

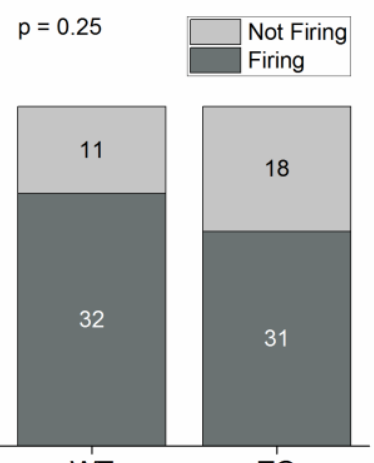

WT
C

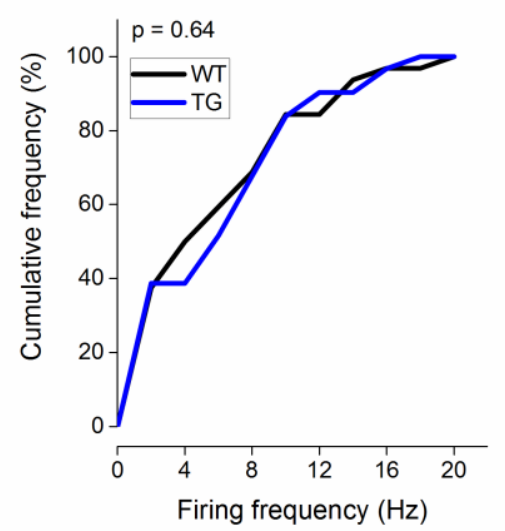

Figure 1. (A) A cumulative frequency plot displaying the distribution of $V_{m}$ observed across groups. Black line represents WT neurons; blue line represents TG neurons. $p$ value was calculated using a Kolmogorov-Smirnov test. (B) A cumulative column representation of the number of silent and spontaneously firing neurons across genotype. $p$ value was calculated using a Chi-squared test. (C) Plot showing, for firing cells, the mean firing frequency for each genotype.

In order to compare passive membrane properties between Re neurons recorded from WT and TG mice, a $500 \mathrm{~ms}, 30 \mathrm{pA}$ hyperpolarising current pulse was passed across the neuronal membrane. For such assessments recordings were made from a set pre-stimulus membrane potential of $-80 \mathrm{mV}$, achieved using a steady state bias current injection. This was to prevent the cell to cell variability in resting membrane potential from introducing variability in intrinsic properties which, as in all neurons, express some degree of voltage-dependence. There were no statistically significant differences observed when comparing the passive properties between WT and TG Re neurons. These cells exhibit 
no Ih mediated sag (Walsh et al 2017) hence the input resistance $\left(R_{i}\right)$ was calculated from Ohm's law by dividing the mean voltage deflection calculated during the last $50 \mathrm{~ms}$ of the $-30 \mathrm{pA}$ hyperpolarising sweep by the amplitude of the negative current injection. Median $R_{i}$ for WT neurons was $426 \mathrm{M} \Omega$ compared to $431 \mathrm{M} \Omega$ for TG neurons (Fig $2 \mathrm{~A}, \mathrm{p}=0.88$, Mann-Whitney $\mathrm{U}$ test). The membrane time constant $(\tau)$ was calculated by fitting a single exponential curve to the charging trajectory of the membrane potential between $20-80 \%$ of the peak amplitude. The median $\tau$ was 29.6 ms for WT neurons as compared to $29.1 \mathrm{~ms}$ for TG neurons (Fig 5.4B, $p=0.35$, Mann-Whitney $U$ test). Membrane capacitance was approximated by calculating the ratio of $\tau / R_{i}$. The median capacitance for WT neurons was $64.0 \mathrm{pF}$ as compared to $54.8 \mathrm{pF}$ for TG neurons (Fig 5.4C, $\mathrm{p}=0.54$, Mann-Whitney U test).

A

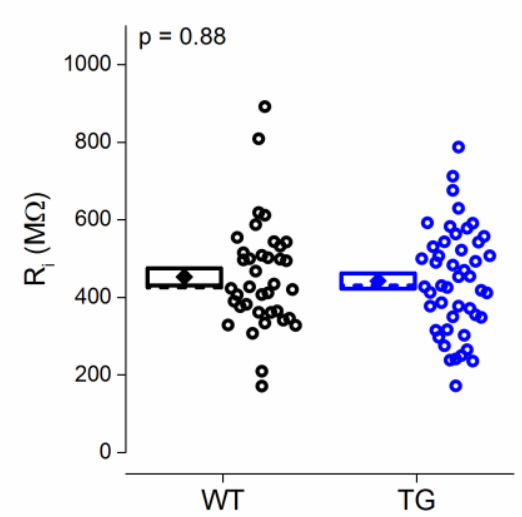

B

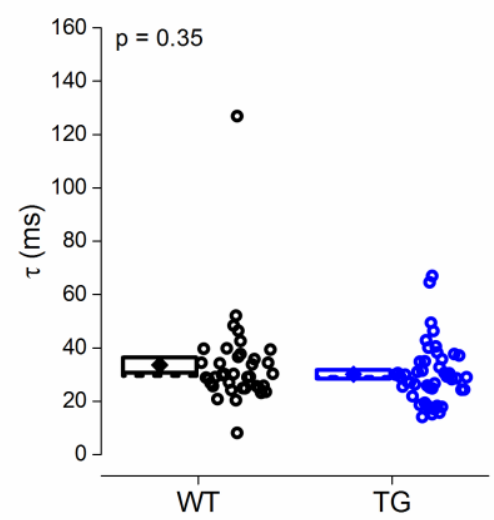

C

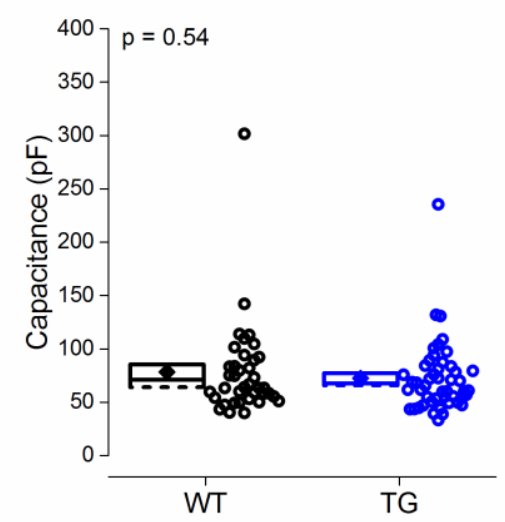

Figure 2. Passive membrane properties were independent of transgene expression. (A-B) Plots of (A) $R_{i}$ and $(B) \tau$, calculated from a $500 \mathrm{~ms}, 30$ pA hyperpolarising current injection. (C) Plot showing capacitance calculated as $\tau / R_{i}$. Diamond represents mean, dashed line represents median, and box represents SEM. All $p$ values were calculated using a Mann-Whitney $U$ test

To compare the excitability of Re neurons between WT and TG mice, a series of incremental depolarising current injections were made ranging in amplitude from 15 to $90 \mathrm{pA}$. These were also applied at a fixed pre-stimulus membrane potential of $-80 \mathrm{mV}$. A sample trace showing the response to a $90 \mathrm{pA}$ current injection is displayed in Figure 3A. The mean number of APs and the latency to the first AP produced in response to the series of current injections were used to quantify excitability. The mean number of APs elicited, calculated for each population by dividing the sum of APs (including zero spike sweeps) produced by population cell count, was not affected by transgene expression (Fig 3B, $W T, n=38 ; T G, n=47 ; F=0.55, p=0.46,2$ way RM-ANOVA). Latency to the first AP was measured in response to the four largest current injections ( $45-90 \mathrm{pA})$, as each resulted in at least one AP in the vast majority of Re neurons in both WT (97\%) and TG $(95 \%)$ mice. Latency was calculated as time taken 
166 from the initiation of the depolarising current stimulus to the peak of the first AP. The latency to the 167 first AP was $~ 32 \%$ shorter in Re neurons recorded from $J 20$ mice (Fig 3C, WT $n=37 ; T G, n=45 ; F=$ $1686.37, p=0.02,2$ way RM-ANOVA). From more depolarised membrane potentials, a sizeable proportion 169 of Re neurons display rebound firing following a 500 ms hyperpolarising current injection. This appears 170 to result largely from the de-inactivation of $\mathrm{T}$-type $\mathrm{Ca}^{2+}$ channels afforded by hyperpolarization (Walsh 171 et al., 2017). To assess whether the propensity for rebound firing was genotype-associated expression, 172 a $500 \mathrm{~ms}, 30 \mathrm{pA}$ hyperpolarising current injection was injected from a set pre-stimulus potential of $17372 \mathrm{mV}$ (Fig 3D), which sits between the overall average resting membrane potential and the mean 174 resting potential of the subgroup of cells that did not exhibit spontaneous firing. TG neurons had a 175 higher propensity to rebound fire than WT neurons (Fig 3E, WT, 39\%; TG, 64\%; $p=0.03$, Chi-squared 176 test). For the cells which exhibited such hyperpolarization induced firing, rebound latency, defined as 177 the time taken from the cessation of the current stimulus to the peak of the first rebound spike, was 178 also calculated. This was significantly shorter in TG (median $112.5 \mathrm{~ms}$ ) as compared to WT (median $179147.4 \mathrm{~ms}$ ) neurons (Fig 5.3D, WT, $n=15 ; \mathrm{TG}, \mathrm{n}=27 ; \mathrm{p}=0.02$, Mann-Whitney $\mathrm{U}$ test). 
A

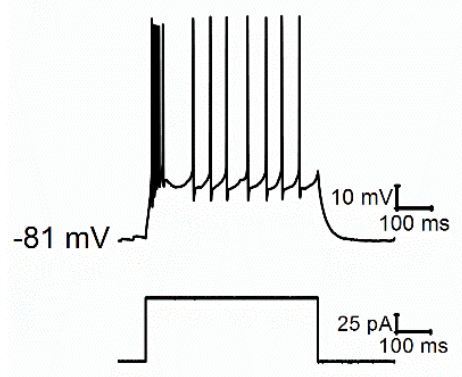

D

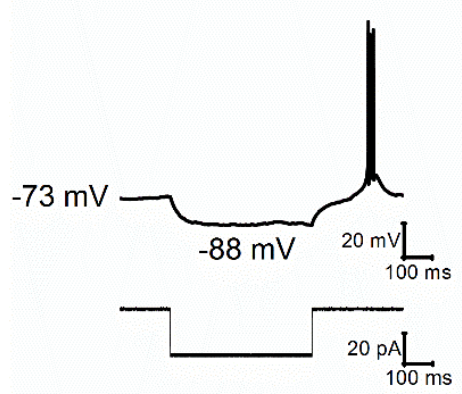

B

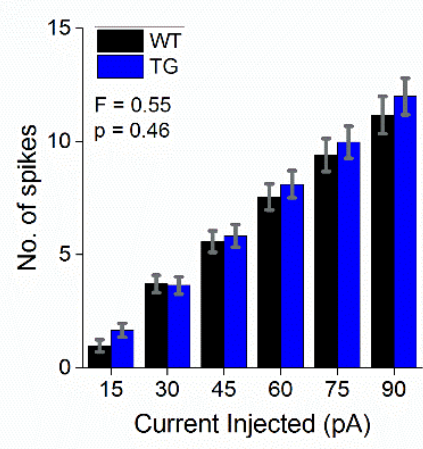

$\mathrm{E}$

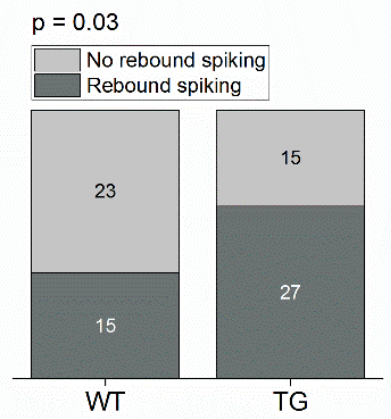

C

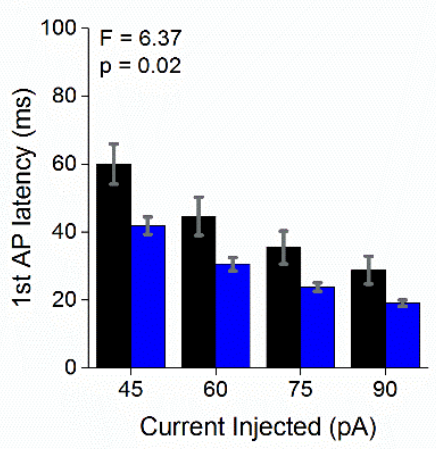

$\mathrm{F}$

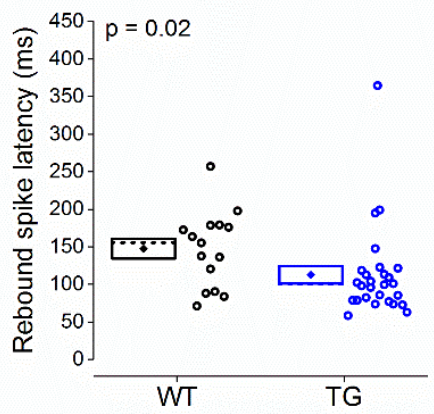

Figure 3. (A) Sample voltage response (top) and current trace (bottom) of a $90 \mathrm{pA}, 500 \mathrm{~ms}$ depolarising current injection from a prestimulus potential of $-80 \mathrm{mV}$. Plots showing (B) the mean number of APs and (C) mean latency to the first AP, produced in response to a series of $500 \mathrm{~ms}$ depolarising current injections from a prestimulus potential of $-80 \mathrm{mV}$. $F$ and $p$ values calculated using a 2 way RM-ANOVA are shown. (D) Sample voltage (top) and current (bottom) trace of a -30 pA, 500 ms hyperpolarising current step from a set membrane potential of $-73 \mathrm{mV}$. (E) A cumulative column representation of the number of neurons which did not exhibit rebound firing and the number of neurons which exhibited rebound firing from a holding potential of $-73 \mathrm{mV}$. $p$ values were calculated using a Chi-squared test. (F) Plot showing the latency to the peak of the $1^{\text {st }}$ rebound spiken. Diamond represents mean, dashed line represents median, and box represents SEM. $p$ value was calculated using a Mann-Whitney $U$ test.

$G A B A_{B}$ receptors are widely expressed throughout the mouse thalamus. When activated at synapses the resultant post-synaptic hyperpolarization can reliably generate rebound burst firing in thalamic relay neurons (Ulrich et al., 2018). A radioligand binding analysis reported many baclofen sensitive GABA binding sites in Re (Hosford et al., 1995), and the same study provided evidence of directionally opposed outcomes of GABAB receptor agonism and antagonism on spike and wave discharges in the lethargic mouse model of absence seizures. Commensurate with this, the Allen Brain Atlas (http://mouse.brain-map.org) indicates that both the subunits required to make the $G A B A_{B}$ receptor are robustly expressed in Re. However to date, a comprehensive characterisation of the synaptic receptors present on Re neurons has not been published. Hence, to confirm a likely neurophysiological role for $\mathrm{GABA}_{B}$ receptors in Re neurons, we recorded neurons from $\sim 8$ month old WT mice and applied $15 \mu \mathrm{M}$ of $\mathrm{GABA}_{\mathrm{B}}$ receptor agonist R-Baclofen (the active enantiomer) via the aCSF perfusing the recording chamber. Following break in to the whole cell mode, Vm was recorded for at least one 
A

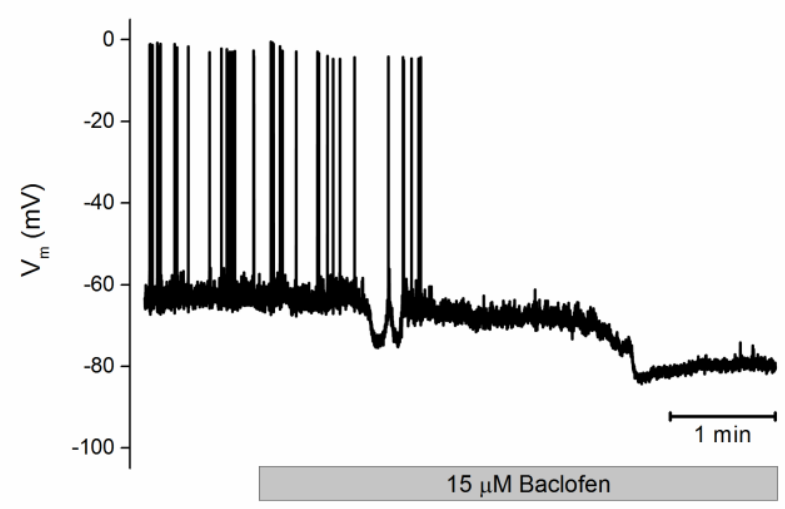

B

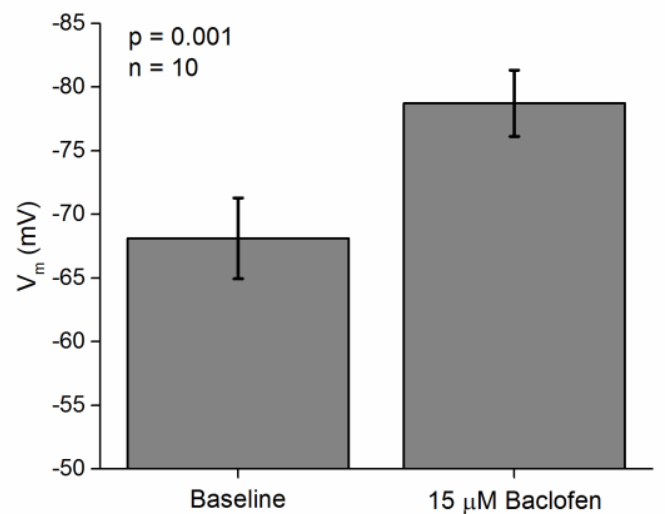

201

Figure 4. (A) Sample Voltage trace showing the effect of $15 \mu \mathrm{M}$ Baclofen on Vm. (B) Bar graph showing the mean effect of Baclofen on Vm. Error bars represent sem. $p$ value was calculated using a paired two tailed Student's t-test.

202

203

204

205

206

207

208

209

210

211

212

213

214

215

216

minute to establish a baseline. Baclofen was then washed on and the cellular response was followed for 5 minutes. Baclofen produced a hyperpolarisation in Re neurons, comparing baseline (mean -68 $\mathrm{mV}$ ) and the fifth minute of application (-78 mV) (Fig $4 B, n=10, p=0.001$, paired, two tailed students t-test), suggesting that Re neurons have the potential to display rebound firing in response to GABABreceptor mediated inhibitory synaptic input. Exogenous baclofen also reduced the variance in the membrane potential likely as a result of reduced presynaptic release of glutamate and/or GABA at synapses made on to Re cells.

As previously mentioned, T-type calcium currents are necessary for rebound firing in Re neurons. We wished to assess whether the increased propensity to rebound fire in TG mice may result from of alterations to the amplitude or kinetics of T-type calcium channels. One would expect that such a change would manifest as an alteration in the number of neurons exhibiting sub-threshold and suprathreshold afterdeoplarisations (ADP), a feature underpinned in Re neurons by T-type calcium conductances (Walsh et al., 2017). In order to quantify ADP amplitude a single spike was elicited with a large (2 $\mathrm{nA})$, short $(1.3 \mathrm{~ms})$ depolarising current injection applied at a set prestimulus potential of $80 \mathrm{mV}$. Neurons were divided into one of three groups qualitatively; in any neuron which lacked a clear depolarising phase following the peak of AP the ADP was interpreted to be zero. Any neuron where the amplitude of the ADP was not sufficiently large to elicit an AP was defined as exhibiting a sub-threshold ADP, while if the ADP was of a great enough amplitude to cross AP threshold it was defined as supra-threshold. The proportion of neurons exhibiting supra-threshold, sub-threshold, or no quantifiable ADP was similar between WT and TG Re neurons (Fig 5A, $p=0.68$, Chi-squared test). Direct quantification of ADP amplitude was restricted to neurons displaying sub-threshold ADPs, as the presence of one or more ADP-driven APs obstructs faithful measurement in the suprathreshold 
population. An average trace of the $V_{m}$ in response to the depolarising current injection in neurons displaying a sub-threshold ADP is displayed in Figure 5B. ADP amplitude did not significantly differ between WT (mean $11.9 \pm 2.0 \mathrm{mV}$ ) and TG (mean $13.0 \pm 1.7 \mathrm{mV}$ ) mice (Fig 5C, WT, $\mathrm{n}=12 ; \mathrm{TG}, \mathrm{n}=18$; $p=0.67$, unpaired, two tailed students t-test).

221 In order to confirm that the activity of T-type calcium channels was unaltered in J20 mice, we carried out a series of voltage-clamp recordings using a $\mathrm{CsMeSO}_{4}$ based internal solution to directly measure the amplitude and voltage-gated kinetics of the low threshold $\mathrm{Ca}^{2+}$ current directly. A series of voltage steps was applied, ranging from -68 to $-40 \mathrm{mV}$, from a holding potential of $-78 \mathrm{mV}$ (see Figure 5D). In response to sufficiently large voltage steps an additional inward current was observed which was evidently larger and displayed longer activation and inactivation kinetics than the inactivating T-type channel currents (Walsh et al., 2017). These likely arise from the initial activation of a large HVA Ca ${ }^{2+}$ channel current component. In an attempt to minimise the confounds of measuring the amplitude of T-type $\mathrm{Ca}^{2+}$ current, analysis was restricted to those voltage steps ranging from $-75 \mathrm{mV}$ to $-46 \mathrm{mV}$, where $\mathrm{HVACa}^{2+}$ current activation was minimal.

The steady state inactivation profile of the channel was studied using a depolarising voltage step to $58 \mathrm{mV}$ from a pre-step potential incrementally increasing from $-98 \mathrm{mV}$ to $-59 \mathrm{mV}$. A representative recording of the evoked currents is displayed in Figure 5E. Average I/V plots of maximal inward current and inactivation curves are displayed in Figure 5F. Visual examination of the curves indicated that there is no clear hyperpolarising or depolarising shift in either plot. In light of the data presented in Figures 4 , one can say with a degree of confidence that alterations the amplitude or voltage-gated kinetics of T-type $\mathrm{Ca}^{2+}$ channels do not play a causal role in the increased propensity of Re neurons to rebound fire. 
A

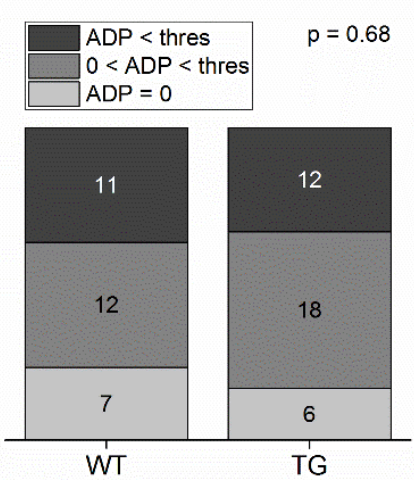

D
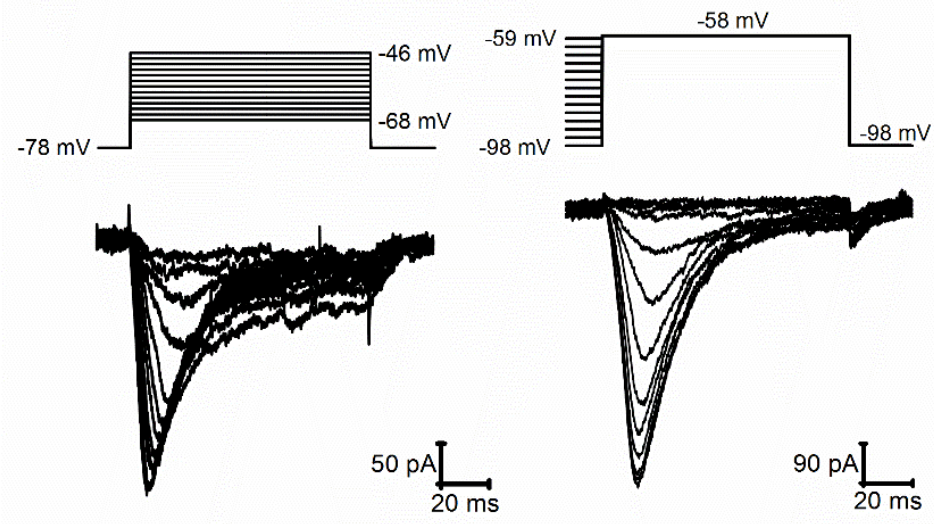

B

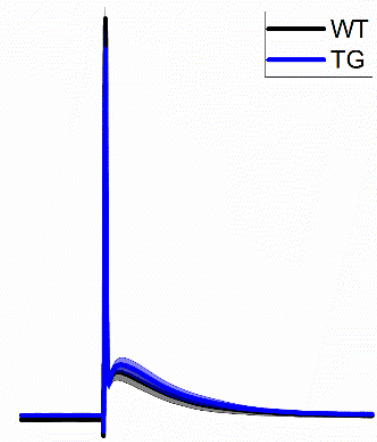

E

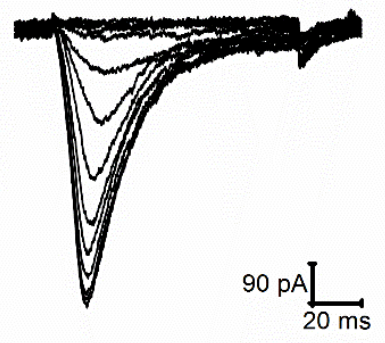

C

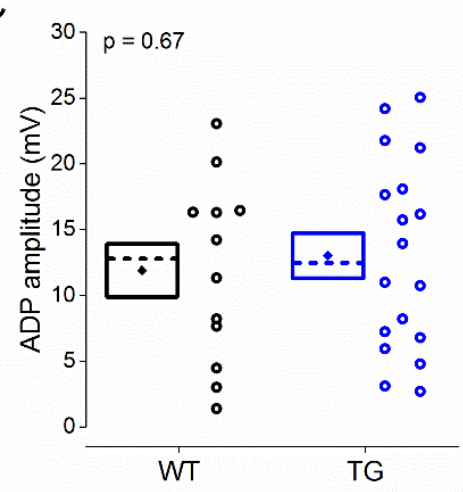

$\mathrm{F}$

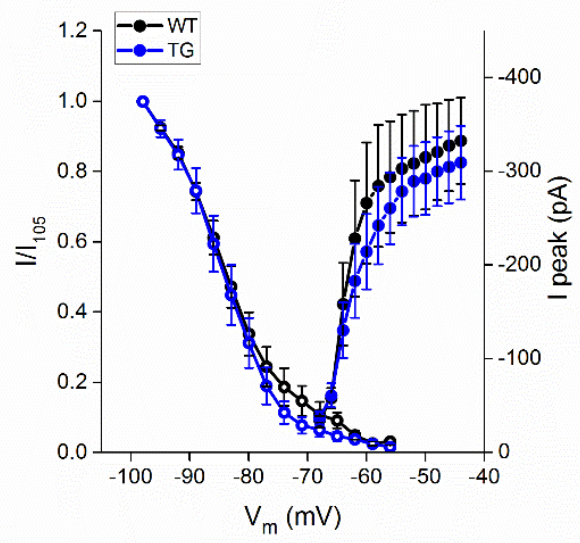

Figure 5. (A) Cumulative column representation of the number of neurons which do not exhibit an $A D P$, the number of neurons exhibiting a subthreshold ADP and the number of neurons which exhibit a suprathreshold ADP across genotype. This was measured from a holding potential of $-80 \mathrm{mV}$ with a $1.25 \mathrm{~ms} 2 \mathrm{nA}$ current stimulus. $\mathrm{p}$ value was calculated using a Chi-squared test. (B) Average voltage trace in response to a short $(1.25 \mathrm{~ms})$, large $(2 \mathrm{nA})$ current injection in cells exhibiting a subthreshold ADP. Line represents mean and shaded area represents SEM. (C) Plot showing the ADP amplitude in neurons exhibiting a subthreshold ADP. Diamond represents mean, dashed line represents median, and box represents SEM. $p$ value was calculated using an unpaired, two tailed student's t-test. (D) Sample voltage trace and the subsequent current response to a series of $2 \mathrm{mV}$ incremental depolarising voltage steps (from $-75--47 \mathrm{mV}$ ) from a prestimulus potential of $-85 \mathrm{mV}$ using a $\mathrm{CsMeSO}_{4}$ based internal solution. (E) Sample voltage trace and the subsequent current responses to a series of depolarising voltage steps to $-65 \mathrm{mV}$ from an incrementally depolarised prestimulus potential (-105 $\mathrm{mV}--66 \mathrm{mV}$ ) were used to calculate the steady state inactivation curve of T-type $\mathrm{Ca}^{2+}$ channels. (F) Average I-V plot (closed circles) of the peak current observed in response to a series of $2 \mathrm{mV}$ voltage steps. Inactivation curve (open circles) showing the average voltage at which T-type $\mathrm{Ca}^{2+}$ channels inactivate.

241 Studies from our lab (and others), have reliably shown that the AP width of CA1 pyramidal neurons is approximately 10-15\% narrower in mouse models of amyloidopathy (Brown et al., 2011; Wykes et al., 2012; Kerrigan et al., 2014; Tamagnini et al., 2015). This is something we have also observed in CA1 cells of J20 mice, CA1 cells in TAS-TPM mice and CA1 pyramids of rTg4510 tauopathy mice (Francesco Tamagnini, unpublished observations). To assess if a similar alteration is present in Re neurons we 
compared the AP waveform properties of WT and TG mice. AP waveform properties were measured from the first spike generated in response to the $90 \mathrm{pA}, 500 \mathrm{~ms}$ current injection from a pre-stimulus potential of $-80 \mathrm{mV}$ (see Fig $3 \mathrm{~A}$ ). The average peak aligned AP waveform is for WT and TG neurons is displayed in Figure 6A, with corresponding phase plot shown in Figure 6D. AP peak was measured as the absolute zenith of the action potential waveform. There was no difference in the AP peak between $\mathrm{WT}$ (mean 18.4 $\pm 1.3 \mathrm{mV}$ ) and TG (mean $17.2 \pm 1.1 \mathrm{mV}$ ) mice (Fig 6B, WT, $\mathrm{n}=38 ; \mathrm{TG}, \mathrm{n}=47 ; \mathrm{p}=0.49$, unpaired, two tailed Student's t-test). AP half-width was measured as AP width at half height of the AP, where height was defined as the voltage difference between AP peak and AP threshold. AP width was approximately 8\% shorter in Re neurons recorded from TG mice (Fig 6C, WT, mean $0.68 \pm 0.02$ $\mathrm{ms}, \mathrm{n}=38 ; \mathrm{TG}$, mean $0.63 \pm 0.01 \mathrm{~ms}, \mathrm{n}=47 ; \mathrm{p}<0.01$, unpaired, two tailed student's t-test). AP threshold was defined as the voltage at which the first derivative of the membrane voltage $(\mathrm{dV} / \mathrm{dt})$ during the AP waveform exceeded $15 \mathrm{mV} / \mathrm{ms}$. AP threshold did not significantly differ between WT

258 (median -52.1 mV) and TG (median -53.1 mV) mice (Fig 6E, WT, $n=38 ; T G, n=47 ; p=0.24$, Mann259 Whitney $\mathrm{U}$ test). Maximal rate of rise ( $\max \mathrm{dV} / \mathrm{dt}$ ) was defined as the peak value of the first derivative of the AP waveform. Max dV/dt did not significantly differ between WT (median $296 \mathrm{mV} / \mathrm{ms}$ ) and TG (median $317 \mathrm{mV} / \mathrm{ms}$ ) mice (Fig 6F, $\mathrm{WT}, \mathrm{n}=38 ; \mathrm{TG}, \mathrm{n}=47 ; \mathrm{p}=0.16$, Mann-Whitney $\mathrm{U}$ test). 
A

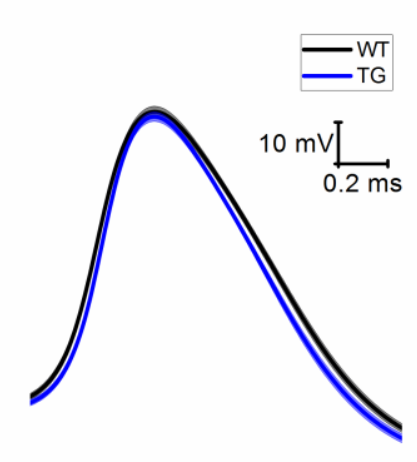

D

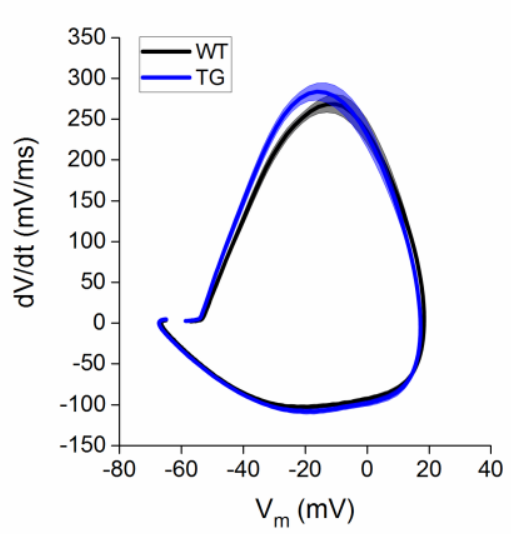

B

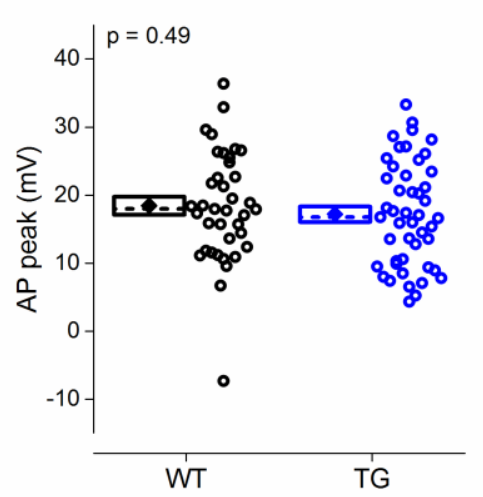

$\mathrm{E}$

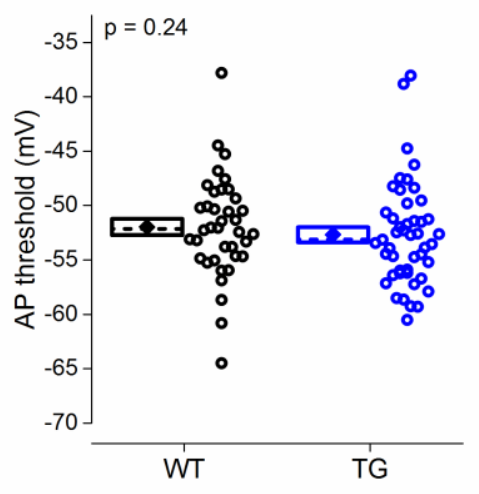

C

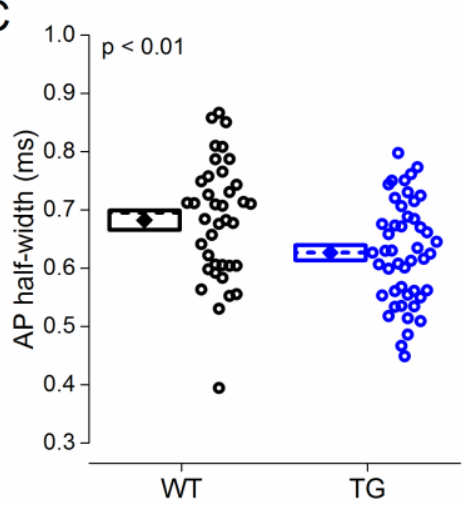

$\mathrm{F}$

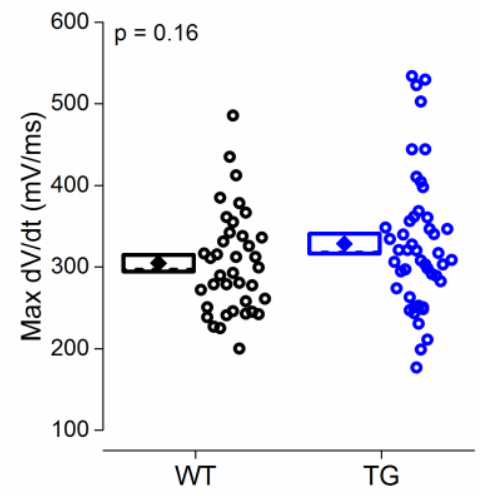

Figure 6. (A) Average waveform of the first AP generated in response to $90 \mathrm{pA}, 500 \mathrm{~ms}$ depolarising current injection. Plots showing (B) the absolute peak voltage value of the AP and (C) the AP width at half height. Diamonds represent means, dashed lines represent medians, and the box outline represents SEM. All $p$ values were calculated using an unpaired, two tailed student's t-test. (D) Average phase plot of first generated AP, plotting the first derivative of the AP voltage against AP voltage. Plots showing (E) the AP threshold and (F) the maximal rate of AP rise. Diamonds represent means, dashed lines represent medians, and the box outline represents SEM. All $p$ values were calculated using a Mann Whitney U test. 
bioRxiv preprint doi: https://doi.org/10.1101/643023; this version posted May 20, 2019. The copyright holder for this preprint (which was not certified by peer review) is the author/funder, who has granted bioRxiv a license to display the preprint in perpetuity. It is made available under aCC-BY-NC-ND 4.0 International license.

265

266

267

268

269

270

271

272

273

274

275

276

277

278

279

280

281

282

283

284

285

286

287

288

289

290

291

292

293

294

295

296

297

\section{Discussion}

Re is integral to normal cognitive processing. This is proposed to be largely underpinned by its influential role within a cognitive network containing the hippocampus, the MPFC and possibly also the subiculum. This study in the widely used $\mathbf{J} 20$ mouse model of amyloidopathy provides the first report of alteration to Re electrophysiology in a mouse model of dementia. Alterations to the intrinsic membrane properties of Re neurons are likely have important consequences for learning and memory. This study indicates that the likelihood that Re neurons will produce burst firing following hyperpolarization (Figure 3), and the AP waveform (Figure 6) are altered in face of an amyloid pathology. A shortening in the latency to fire for a given depolarizing stimulus was also noted in the disease model, which is a likely indication of somewhat heightened excitability (Figure 3 ) and could also change spike timings within reciprocally connected networks.

These novel findings indicate that, in addition to synaptic and network dysfunction previously identified in brain regions more typically associated with memory (e.g. HPC), alterations to the intrinsic cellular electrophysiological properties of Re neurons may contribute to the well-characterised cognitive deficits exhibited by $\mathrm{J} 20$ mice (Cheng et al., 2007; Verret et al., 2012), and by extension potentially those experienced by sufferers of $A D$. Alterations to intrinsic properties of a neuronal population by definition arise downstream from changes to the expression/activity of the myriad voltage-gated ion channels present on neuronal membranes. Our own work (Walsh et al., 2017) indicates that Re neurons appear to differ in significant ways from the much more widely studied relay neurons within sensory aspects of the thalamus. For example, they have a higher input resistance and seem to entirely lack HCN channels and a resulting "sag" potential they generate. Although a start has been made, a comprehensive understanding of the ionic conductances that shape various aspects of the neurophysiology of Re neurons is lacking. Analysis of the channelome in a single cell-level RNA sequencing analysis would be instructive in this regard, and an additional comparative dataset from age-matched J20 mice may help shed light on the neurophysiological outcomes outlined here. However, in the absence of these molecular and associated electrophysiological data, this study confines itself to providing a first descriptive account of intrinsic alterations to Re neurons in J20 mice.

\section{Increased propensity of Re neurons to burst fire}

Potentially the most impactful finding of this study is the finding that Re neurons in J20 mice may display enhanced burst firing in vivo in response to both depolarising and hyperpolarising stimuli. As previously described (Walsh et al., 2017), most Re neurons in adult brain slices typically display a relatively depolarised $V_{m}$ and consequent propensity to tonically fire spontaneous APS in the theta frequency range. Similarly to typical thalamic relay nuclei, the membrane potential of Re neurons 
dictates whether they display tonic or burst firing when depolarised. At more hyperpolarised resting potentials, T-type calcium channels are available to activate in response to sufficient depolarisation resulting in a high-frequency burst of action potentials, which can be as fast as $300 \mathrm{~Hz}$. Conversely, at more depolarised resting potentials, T-type calcium channels reside in inactivated states resulting in relatively low frequency tonic firing in response to depolarising stimuli. In 120 mice, a greater proportion of Re neurons exhibited a hyperpolarised membrane potential than WT controls and consequently, the proportion of Re neurons predisposed to high frequency burst firing $(=<-80 \mathrm{mV})$ is greater in the disease model.

Similarly, Re neurons (along with typical thalmic relay neurons) can readily display bursting behaviour following a prolonged (500 ms - 1s) hyperpolarising current stimulus. This results from the recovery from inactivation (i.e. deinactivation) of T-type calcium channels during the hyperpolarising step. The increased propensity of Re neurons to display rebound spiking in response to hyperpolarising current injections indicates Re neurons are also highly likely to display increased rates of burst firing in response to hyperpolarising stimuli in vivo. But what hyperpolarizing influence might deinactivate $\operatorname{Re}$ neurons $\mathrm{LVA} \mathrm{Ca}^{2+}$ channels in vivo and lead to such high frequency rebound burst firing? Re neurons unquestionably lack the long-lasting, post-burst, $\mathrm{Ca}^{2+}$-dependent, afterhypolarizations exhibited by some other CNS neurons; indeed they generally exhibit marked post burst ADPs instead. Consequently, we propose the most likely source of sufficiently prolonged and large hyperpolarisations of Re neurons is synaptic activation of postsynaptic $G A B A_{B}$ receptors. Re neurons certainly receive GABAergic inputs, for example, at room temperature, spontaneous miniature $G A B A_{A}$ receptor-mediated IPSCs have been recorded at circa $2 \mathrm{~Hz}$ under recording conditions (i.e. intracellular $\mathrm{CS}^{+}$) where $\mathrm{GABA}_{B}$ receptors would be blocked (Xu \& Südhof, 2013). In our recordings from cells at physiological temperature, using $\mathrm{K}^{+}$-containing pipette solutions, Re neurones exhibit spontaneous GABAergic iPSCs at approximately $10 \mathrm{~Hz}$ in the absence of TTX. Indeed, the impact of inhibitory synaptic drive is exemplified by significant relationship between chloride equilibrium potential and the resting potential of Re neurons ( $D W$ and $A R$, unpublished observations). Furthermore, $a$ manipulation (local virally-mediated Neuroligin 2 knockdown) that reduces GABAergic drive to Re has significant behavioural outcomes ( $\mathrm{Xu}$ and Sudhof, 2013). We are unaware of any direct neurophysiological demonstration of $\mathrm{GABA}_{B}$-mediated IPSPs in Re neurons, although our data (Figure 4) indicate the required coupling of $\mathrm{GABA}_{B}$ receptors to $\mathrm{K}^{+}$channels appears to be present. It would be interesting to develop a method to evoke monosynaptic IPSPs in Re neurons in slices, perhaps using an optogenetic strategy.

A number of lines of evidence support the assertion that the output mode (tonic vs burst firing) of Re neurons can profoundly influence both hippocampal and cortical activity. Burst firing in thalamic relay 
bioRxiv preprint doi: https://doi.org/10.1101/643023; this version posted May 20, 2019. The copyright holder for this preprint (which was not certified by peer review) is the author/funder, who has granted bioRxiv a license to display the preprint in perpetuity. It is made available under aCC-BY-NC-ND 4.0 International license.

nuclei in response to hyperpolarising current is associated with both thalama-cortical delta oscillations, commonly seen during slow wave sleep, and spike and wave discharges (SWDs) observed during absence seizures. Notably increasing the power of Re delta oscillations by infusion of NMDA antagonist ketamine can impose delta oscillations onto the hippocampus. Similarly direct optogenetic activation of Re at delta frequency can impose an increase in delta power upon the HPC, resulting in cognitive deficits (Duan et al., 2015). Meanwhile in a mouse model of atypical absence epilepsy in which $\mathrm{GABA}_{B}$ receptors are overexpressed post-natally, the emergence of SWDs within a corticothalamo-hippocampal circuit and associated cognitive deficits are dependant of the activity of $G A B A_{B}$ receptors in the midline thalamus (including Re) (Hosford et al., 1995; Wang et al., 2009).

Recently, a study which focused on the contribution of the thalmo-cortical system to seizure activity in J20 mice identified a 3-4 fold increase in spontaneous Re activity. Since both cognitive deficits and non-convulsive seizures (with associated SWDs) are reliable phenotypes reported in J20 mice, this present study raises the intriguing possibility that it is an increase in the propensity of Re neurons to burst fire that plays a causal role in the memory impairments and seizure activity seen in J20 mice. It would be of significant interest to perform longitudinal in vivo recordings of single unit activity in Re of J20 mice. Deep brain stimulation (DBS) has previously been used to reduce regional rebound bursting to great therapeutic effect in Parkinson's disease (Meijer et al., 2011; Cury et al., 2017). This raises the intriguing possibility that DBS of Re could be a viable therapeutic strategy in the treatment of AD. Support for this notion is provided by a study by Arrieta-Cruz et al. (2010) who showed that 25 $\mathrm{Hz}$ deep brain stimulation of the midline thalamus facilitated acquisition of object recognition memory in the TgCRND8 mouse model of amyloidopathy.

\section{Excitability}

With Re neurons preset to $-80 \mathrm{mV}$ no significant changes to the passive membrane properties or number of spikes elicited in response to a series of depolarising current injections in J20 mice were observed. There was, however, a $30 \%$ decrease in the latency to the $1^{\text {st }}$ spike both following initiation of depolarising stimuli and cessation of a hyperpolarising stimulus. As the predominant firing frequency observed over the entire course of a $500 \mathrm{~ms}$ depolarising stimulus in Re neurons is approximately $20 \mathrm{~Hz}$, the $10-20 \mathrm{~ms}$ decrease in first spike latency is unlikely to manifest as an appreciable increase in spiking rate in response to prolonged depolarisation. This raises the interesting question as to whether the decrease in spike latency reported is likely to alter, in some fundamental sense, the information Re neurons transmit within cognitive networks. Notably such a change in latency could be more impactful when the source of depolarization is in the form of the transient current flux underpinning the depolarizing envelope of an EPSP rather than a "square-wave" current 
stimuli most typically used in experimental work. Firstly, this could result in a greater likelihood of a spike occurring at all for near threshold synaptic events, whereas for more robust excitatory inputs spike timing could be altered. Certainly whether spike timing or gross spike rate represent the fundamental unit of neural computation in the CNS is still the subject of debate within the neuroscientific community (London et al., 2010; Bruno, 2011; Brette, 2015).

The more immediate question to our eyes is whether alterations to the excitability profile of $\mathrm{Re}$ neurons contribute to the increased risk of seizure activity commonly observed following prolonged exposure to increased $A \beta$ load in both mouse and human. A primary motivation in the study of neuronal excitability in mouse models of $A D$, certainly within our lab, has been to try and link alterations at a neuronal level to hyperexcitability observed in hippocampal and cortical networks. Re neurons appear hyperexcitable in J20 mice and studies show that excess excitation of Re neurons results in increased propensity of convulsive seizures (Hirayasu \& Wada, 1992; Luna-Munguia et al., 2017). However the evidence presented in this work does not support the view that Re hyperexcitability in response to depolarising stimuli contributes to the increased seizure rates in J20 mice.

\section{Alterations in AP waveform}

This study also uncovers the novel finding that the AP waveform of Re neurons is significantly narrower in $\mathrm{J} 20$ mice. The approximate $8 \%$ reduction in Re spike width is reminiscent of the spike narrowing of hippocampal CA1 pyramidal neurons in other mouse models of amyloidopathy, including PSAPP, PDAPP, CRND8 (Brown et al., 2011; Wykes et al., 2012; Kerrigan et al., 2014; Tamagnini et al., 2015), and indeed J20 mice (F. Tamagninini and AR, unpublished data). This finding was unexpected, as thalamic neurons differ substantially from CA1 pyramidal neurons in their expression profile of voltage-gated ion channels. The concordance in these findings both across models of amyloidopathy within CA1, and now across CA1 and Re in $\mathrm{J} 20$ mice suggests that the narrowing of APs is a reliable and potentially widespread phenomenon across the CNS in response to excess A $\beta$ levels. Indeed we have also seen a similar change in some hippocampal GABAergic interneurons (Francesco Tamagnini and $A R$, unpublished observations).

Following initiation of an $\mathrm{AP}$, a plethora of voltage-gated $\mathrm{Na}^{+}, \mathrm{K}^{+}$and $\mathrm{Ca}^{2+}$ are recruited. Given the kinetics of the voltage-gated $\mathrm{Ca}^{2+}$ channels activated, $\mathrm{Ca}^{2+}$ flux across the membrane increases in an exponential fashion over the duration of the waveform. Indeed mathematical modelling of experimental data has suggested that a similarly modest decrease in spike width (10-15\%) in CA1 neurons can lead to up to a $40 \%$ reduction in $\mathrm{Ca}^{2+}$ entry during an AP (Kerrigan et al., 2014). $\mathrm{Ca}^{2+}$ ions are vital for an array of normal cellular processes and a decrease in $\mathrm{Ca}^{2+}$ entry would undoubtedly have marked effects in normal cellular functioning. For example, given the assumption that APs 
recorded at the soma reflect the AP waveforms that subsequently arrive in presynaptic terminals, reduced $\mathrm{Ca}^{2+}$ flux resulting from a narrower AP would lead to a reduction in the probability of neurotransmitter release. This will likely reduce the ability of Re to influence the activity of its various downstream targets including hippocampal area CA1 and the MPFC. For example, although studies focusing on alterations in basal synaptic transmission to CA1 in J20 have focused exclusively on the Schaffer Collateral (CA3 $\rightarrow$ CA1) pathway, a reduction in Re neurotransmitter release would likely manifest itself as a reduction in the amplitude of a field EPSP recorded following stimulation of presumed temporoammonic (EC $\rightarrow$ CA1) fibres in acute hippocampal slices. Such a finding would could interpreted falsely as an alteration to entorhinal cortex input to CA1.

\section{Limitations of in vitro recordings}

Recordings made in brain slices are both high-throughput and convenient when compared to comparable in vivo alternatives. As such, we feel that this preparation is perfectly suited to this initial characterisation of alterations to Re intrinsic neurophysiological properties in a mouse model of dementia. However caution should be taken before extrapolating results viewed in vitro, where many inter-region connections are severed, to expected activity within an intact functioning neuronal network. This is especially true in thalamic neurons whose $V_{m}$ (and associated functional output) is highly malleable in the face of excitatory and inhibitory modulatory input (Sherman \& Guillery, 2006). For example, recent evidence suggests activation of mPFC-Re connections modulates burst firing in Re (Zimmerman \& Grace, 2018). An important next step will be identifying which of the changes presented in this work are also evident in vivo. Importantly, doing so would allow these alterations to be correlated directly with behavioural deficits. In vivo, comparable alterations would likely have functional consequences within cognitive networks as an ever building literature suggests that the activity of Re can profoundly influence both hippocampal and cortical activity (Hosford et al., 1995; Drexel et al., 2011; Zhang et al., 2012; Duan et al., 2015).

(1)

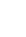




\section{References}

Aggleton JP (2014). Looking beyond the hippocampus: old and new neurological targets for understanding memory disorders. Proc Biol Sci; DOI: 10.1098/rspb.2014.0565.

Aggleton JP \& Brown MW (1999). Episodic memory, amnesia, and the hippocampal-anterior thalamic axis. Behav Brain Sci 22, 425-44-89.

Arrieta-Cruz I, Pavlides C \& Pasinetti GM (2010). DEEP BRAIN STIMULATION IN MIDLINE THALAMIC REGION FACILITATES SYNAPTIC TRANSMISSION AND SHORTTERM MEMORY IN A MOUSE MODEL OF ALZHEIMER'S DISEASE. TransI Neurosci 1, 188-194.

Brette R (2015). Philosophy of the Spike: Rate-Based vs. Spike-Based Theories of the Brain. Front Syst Neurosci 9, 151.

Brown JT, Chin J, Leiser SC, Pangalos MN \& Randall AD (2011). Altered intrinsic neuronal excitability and reduced $\mathrm{Na}+$ currents in a mouse model of Alzheimer's disease. Neurobiol Aging 32, 2109.e1-2109.e14.

Bruno RM (2011). Synchrony in sensation. Curr Opin Neurobiol 21, 701-708.

Cassel J-C, Pereira de Vasconcelos A, Loureiro M, Cholvin T, Dalrymple-Alford JC \& Vertes RP (2013). The reuniens and rhomboid nuclei: Neuroanatomy, electrophysiological characteristics and behavioral implications. Prog Neurobiol 111, 34-52.

Cheng IH, Scearce-Levie K, Legleiter J, Palop JJ, Gerstein H, Bien-Ly N, Puoliväli J, Lesné S, Ashe KH, Muchowski PJ \& Mucke L (2007). Accelerating Amyloid- $\beta$ Fibrillization Reduces Oligomer Levels and Functional Deficits in Alzheimer Disease Mouse Models. J Biol Chem 282, 23818-23828.

Cholvin T, Loureiro M, Cassel R, Cosquer B, Geiger K, De Sa Nogueira D, Raingard H, Robelin L, Kelche C, Pereira de Vasconcelos A \& Cassel J-C (2013). The ventral midline thalamus contributes to strategy shifting in a memory task requiring both prefrontal cortical and hippocampal functions. J Neurosci 33, 8772-8783.

Cury RG, Fraix V, Castrioto A, Pérez Fernández MA, Krack P, Chabardes S, Seigneuret E, Alho EJL, Benabid A-L \& Moro E (2017). Thalamic deep brain stimulation for tremor in Parkinson disease, essential tremor, and dystonia. Neurology 89, 1416-1423.

Drexel M, Preidt AP, Kirchmair E \& Sperk G (2011). Parvalbumin interneurons and calretinin fibers arising from the thalamic nucleus reuniens degenerate in the subiculum after kainic acidinduced seizures. Neuroscience 189, 316-329. 
Duan AR, Varela C, Zhang Y, Shen Y, Xiong L, Wilson M \& Lisman J (2015). Delta frequency optogenetic stimulation of a thalamic nucleus reuniens is sufficient to produce working memory deficits; relevance to schizophrenia. Biol Psychiatry 77, 1098-1107.

Hallock HL, Wang A \& Griffin AL (2016). Ventral Midline Thalamus Is Critical for HippocampalPrefrontal Synchrony and Spatial Working Memory. J Neurosci 36, 8372-8389.

Hallock HL, Wang A, Shaw CL \& Griffin AL (2013). Transient inactivation of the thalamic nucleus reuniens and rhomboid nucleus produces deficits of a working-memory dependent tactilevisual conditional discrimination task. Behav Neurosci 127, 860-866.

Hardy JA \& Higgins GA (1992). Alzheimer's disease: the amyloid cascade hypothesis. Science 256, 184-185.

Hazra A, Corbett BF, You JC, Aschmies S, Zhao L, Li K, Lepore AC, Marsh ED \& Chin J (2016). Corticothalamic network dysfunction and behavioral deficits in a mouse model of Alzheimer's diseHazra A, Corbett BF, You JC, Aschmies S, Zhao L, Li K, Lepore AC, Marsh ED \& Chin J (2016). Corticothalamic network dysfunction and behavioral deficits in a mo. Neurobiol Aging 44, $96-$ 107.

Hembrook JR \& Mair RG (2011). Lesions of reuniens and rhomboid thalamic nuclei impair radial maze win-shift performance. Hippocampus 21, 815-826.

Hirayasu Y \& Wada JA (1992). N-methyl-D-aspartate injection into the massa intermedia facilitates development of limbic kindling in rats. Epilepsia 33, 965-970.

Hong S, Beja-Glasser VF, Nfonoyim BM, Frouin A, Li S, Ramakrishnan S, Merry KM, Shi Q, Rosenthal A, Barres BA, Lemere , Cynthia A., Selkoe DJ \& Stevens B (2016). Complement and microglia mediate early synapse loss in Alzheimer mouse models. Science (80- ). Available at: http://science.sciencemag.org/content/early/2016/03/30/science.aad8373.full [Accessed June 21, 2017].

Hosford DA, Lin FH, Kraemer DL, Cao Z, Wang Y \& Wilson JT (1995). Neural network of structures in which GABAB receptors regulate absence seizures in the lethargic $(\mathrm{lh} / \mathrm{lh})$ mouse model. J Neurosci 15, 7367-7376.

Ito HT, Zhang S-J, Witter MP, Moser El \& Moser M-B (2015). A prefrontal-thalamo-hippocampal circuit for goal-directed spatial navigation. Nature 522, 50-55.

Jacobsen JS, Wu C-C, Redwine JM, Comery TA, Arias R, Bowlby M, Martone R, Morrison JH, Pangalos MN, Reinhart PH \& Bloom FE (2006). Early-onset behavioral and synaptic deficits in a mouse 
model of Alzheimer's disease. Proc Natl Acad Sci 103, 5161-5166.

491

492

493

Jankowski MM, Islam MN, Wright NF, Vann SD, Erichsen JT, Aggleton JP \& O’Mara SM (2014). Nucleus reuniens of the thalamus contains head direction cells. Elife; DOI: 10.7554/eLife.03075.

Jankowski MM, Passecker J, Islam MN, Vann S, Erichsen JT, Aggleton JP \& O’Mara SM (2015). Evidence for spatially-responsive neurons in the rostral thalamus. Front Behav Neurosci 9, 256.

Kafetzopoulos V, Kokras N, Sotiropoulos I, Oliveira JF, Leite-Almeida H, Vasalou A, Sardinha VM, Papadopoulou-Daifoti Z, Almeida OFX, Antoniou K, Sousa N \& Dalla C (2018). The nucleus reuniens: a key node in the neurocircuitry of stress and depression. Mol Psychiatry 23, 579586.

Kerrigan TL, Brown JT \& Randall AD (2014). Characterization of altered intrinsic excitability in hippocampal CA1 pyramidal cells of the A $\beta$-overproducing PDAPP mouse. Neuropharmacology 79, 515-524.

London M, Roth A, Beeren L, Häusser M \& Latham PE (2010). Sensitivity to perturbations in vivo implies high noise and suggests rate coding in cortex. Nature 466, 123-127.

Luna-Munguia H, Starski P, Chen W, Gliske S \& Stacey WC (2017). Control of in vivo ictogenesis via endogenous synaptic pathways. Sci Rep 7, 1311.

McGowan E, Eriksen J \& Hutton M (2006). A decade of modeling Alzheimer's disease in transgenic mice. Trends Genet 22, 281-289.

Meijer HGE, Krupa M, Cagnan H, Lourens MAJ, Heida T, Martens HCF, Bour LJ \& van Gils SA (2011). From Parkinsonian thalamic activity to restoring thalamic relay using deep brain stimulation: new insights from computational modeling. J Neural Eng 8, 66005.

Mucke L, Masliah E, Yu GQ, Mallory M, Rockenstein EM, Tatsuno G, Hu K, Kholodenko D, JohnsonWood K \& McConlogue L (2000). High-level neuronal expression of abeta 1-42 in wild-type human amyloid protein precursor transgenic mice: synaptotoxicity without plaque formation. $J$ Neurosci 20, 4050-4058.

Palop JJ \& Mucke L (2009). Epilepsy and cognitive impairments in Alzheimer disease. Arch Neurol 66, 435-440.

Pereira de Vasconcelos A \& Cassel J-C (2015). The nonspecific thalamus: A place in a wedding bed for making memories last? Neurosci Biobehav Rev 54, 175-196.

Randall AD, Witton J, Booth C, Hynes-Allen A \& Brown JT (2010). The functional neurophysiology of 
Roy A, Svensson FP, Mazeh A \& Kocsis B (2017). Prefrontal-hippocampal coupling by theta rhythm Brain Struct Funct; DOI: 10.1007/s00429-017-1374-6.

Saganich MJ, Schroeder BE, Galvan V, Bredesen DE, Koo EH \& Heinemann SF (2006). Deficits in Synaptic Transmission and Learning in Amyloid Precursor Protein (APP) Transgenic Mice Require C-Terminal Cleavage of APP. J Neurosci 26, 13428-13436.

Selkoe DJ \& Hardy J (2016). The amyloid hypothesis of Alzheimer's disease at 25 years. EMBO Mol Med 8, 595-608.

Sherman SM \& Guillery RW (2006). Exploring the thalamus and its role in cortical function. The MIT Press, Cambridge, MA.

Tamagnini F, Novelia J, Kerrigan TL, Brown JT, Tsaneva-Atanasova K \& Randall AD (2015). Altered intrinsic excitability of hippocampal CA1 pyramidal neurons in aged PDAPP mice. Front Cell Neurosci 9, 372.

Ulrich D, Lalanne T, Gassmann M \& Bettler B (2018). GABA B receptor subtypes differentially

Verret L, Mann EO, Hang GB, Barth AMI, Cobos I, Ho K, Devidze N, Masliah E, Kreitzer AC, Mody I, Mucke L \& Palop JJ (2012). Inhibitory Interneuron Deficit Links Altered Network Activity and Cognitive Dysfunction in Alzheimer Model. Cell 149, 708-721.

Vertes RP, Linley SB \& Hoover WB (2015). Limbic circuitry of the midline thalamus. Neurosci Biobehav Rev; DOI: 10.1016/j.neubiorev.2015.01.014.

Walsh DA, Brown JT \& Randall AD (2017). In vitro characterization of cell-level neurophysiological diversity in the rostral nucleus reuniens of adult mice. J Physiol 595, 3549-3572.

Wang X, Stewart L, Cortez MA, Wu Y, Velazquez JLP, Liu CC, Shen L \& Snead OC (2009). The circuitry of atypical absence seizures in GABABR1a transgenic mice. Pharmacol Biochem Behav 94, 124130.

Witton J, Brown JT, Jones MW \& Randall AD (2010). Altered synaptic plasticity in the mossy fibre pathway of transgenic mice expressing mutant amyloid precursor protein. Mol Brain 3, 32 . 

mouse model of Alzheimer's disease. PLoS One 8, e59586.

551 Wykes R, Kalmbach A, Eliava M \& Waters J (2012). Changes in the physiology of CA1 hippocampal pyramidal neurons in preplaque CRND8 mice. Neurobiol Aging 33, 1609-1623.

553 Xu W \& Südhof TC (2013). A neural circuit for memory specificity and generalization. Science 339, $554 \quad 1290-1295$.

Zhang Y, Yoshida T, Katz DB \& Lisman JE (2012). NMDAR antagonist action in thalamus imposes $\delta$ oscillations on the hippocampus. J Neurophysiol 107, 3181-3189.

557

Zimmerman EC \& Grace AA (2018). Prefrontal cortex modulates firing pattern in the nucleus 3255-3272.

560 Funding: Grant sponsor: Eli Lilly and Company and the University of Exeter.

561 Conflict of interest statement: The authors declare that this work was completed with the absence of any conflicting interests, financial or otherwise. 